\title{
Research
}

\section{The Influence of an Orienting Task on the Memory Performance of Children with Reading Problems}

Joseph K. Torgesen, PhD, Harry A. Murphy, MS, and Charles Ivey, BS

This study investigated the hypothesis that differences in performance between reading disabled and normal children on a rote memory task could be eliminated if both groups were induced to process the material to be remembered in the same manner. The free recall of fourth-grade good and poor readers was tested following a free study period and the performance of an orienting task that required subjects to sort the material into taxonomic categories. There was a significant group by conditions interaction, with recall differences in the free study condition being eliminated following performance of the orienting task. The results have important implications for theoretical explanations of performance deficits in reading disabled children.

$\mathbf{R}$ esearch investigating the psychological correlations of learning disabilities has consistently shown that children who experience difficulty learning to read also perform poorly on tasks designed to measure short-term memory (Torgesen 1975). These performance deficits have often been interpreted to mean that poor readers have reduced memory capacities. However, several recent studies have indicated that the performance problems of poor readers may actually be caused by their failure to adapt in an active and organized way to the information processing demands of the tasks.
Torgesen (1977) found important differences between groups of fourth-grade reading disabled and normal children in their tendencies to organize material during study periods and their use of verbalization and rehearsal as mnemonic strategies. Torgesen and Goldman (1977) also found second-grade reading disabled children less likely than children of normal reading skill to use rehearsal as a mnemonic aid on a sequential memory task. A study by Tarver, Hallahan, and Kaufman (1976) showed that learning disabled children develop more slowly than normal children in their use of efficient encoding strategies such as verbal rehearsal.

Differences in recall performance associated with differences in the memorization, or encoding, activities of reading disabled and normal children can be understood quite clearly in light of recent theoretical developments in the experimental study of memory processes. In particular, Craik and Lockhart (1972) have developed a view of memory that proposes that the strength of the memory trace depends on the "depth" to which the material to be remembered is processed. Depth of processing refers to the amount of perceptual or cognitive analysis that is performed on a stimulus. Various mnemonic strategies aid memory in that they either retain an item at a given level of processing (simple rehearsal) or involve activities that require more complex processing of the stimuli. 
If many of the differences in recall performance between good and poor readers occur because children in the two groups process material to be remembered in different ways, it should be possible to reduce differences in recall if differences in initial processing are eliminated. In fact, two previous studies (Torgesen 1977, Torgesen \& Goldman 1977) have shown that differences in recall performance-between skilled and less skilled readers may be significantly reduced if both groups are taught or encouraged to use ef ficient mnemonic strategies. However, because of difficulties in monitoring the actual application of strategies in the two previous studies, it is possible that small but consistent residual differences in recall may have been the result of continuing differences in the processing activities of good and poor readers.

The purpose of this investigation was to study the memory performance of reading disabled and normal children under conditions that more accurately controlled processing of the material to be remembered. As an alternative to instructing children in the use of efficient strategies, they were asked to perform an orienting task prior to having their recall tested. The particular orienting task used in this study required the children to engage in an activity (sorting of items into taxonomic categories) that required relatively complex conceptual analysis of the stimuli to be remembered. As a control to reduce differences in other strategies related to preparation for recall, the children were not told they would be required to recall the stimuli prior to the task. To establish a baseline for performance under conditions where no particular processing instructions were given, children in each reading group were also given a standard-free recall task.

\section{METHOD}

\section{Subject Selection}

Subjects were chosen from five elementary schools in predominantly middle-class areas of Tallahassee, Florida. A large group of fourthgrade boys who had previously been identified by their teacher as average and poor readers were screened using the Culture Fair Intelligence Test of the Institute for Personality and Ability Testing (Cattell \& Cattell 1960). Only those children who obtained an intelligence estimate within an average range (90 to 120) were included in the final sample. Reading level was assessed by the Wide Range Achievement Test (Jastak, Bijou, \& Jastak 1975). Children were categorized as reading disabled if their gradelevel score on this test was 3.5 (all children were tested at midyear) or below, and they had been named by their teacher as having reading problems.

The means and standard deviations for intelligence test score, reading grade level, and chronological age of the reading disabled group were as follows: IQ, $\bar{X}=103.6, S D=7.5$; reading grade level, $\bar{X}=2.8, S D=.7 ; C A, \bar{X}=113, S D=4.7$. The corresponding means and standard deviations for the normal readers were IQ, $\bar{X}=105.5$, $S D=5.2$; reading grade level, $\bar{X}=6.3, S D=1.1$; CA, $X=112, S D=5.1$. The only measure on which the groups were significantly different was reading level, $t(36)=11.7, p<.001$. There were 19 boys in each of the reading groups.

\section{Materials and Apparatus}

All experimental testing was done in a laboratory trailer equipped with a one-way vision mirror. The stimulus materials for the two memory tasks were two different sets of 24 pictures of common objects. Each set of pictures, composed of six objects belonging to each of four conceptual categories, was used for half of the subjects in each group on each task. A complete description of these materials is contained in an earlier report (Torgesen 1977).

In addition to the stimulus cards, a $31 \times 61 \mathrm{~cm}$ wooden tray was used during the free study task. The stimulus materials were arranged on this tray. Four $8 \times 58 \mathrm{~cm}$ hardboard strips were used during the sorting task. Each strip had four $8 \times$ $8 \mathrm{~cm}$ blue squares of construction paper equally spaced along its length. For each task, a blue cloth approximately $48 \times 80 \mathrm{~cm}$ was used to cover the stimulus materials during recall. 
Procedure - First

\section{Experimental Session}

The procedures used for the free recall task were similar to those employed in an earlier study of memorization activities in poor readers (Torgesen 1977). Following a practice trial using different stimuli, a group of 24 pictures was presented briefly to the subject in a circular array. The subject was asked to name the pictures and was instructed to study the stimuli so that they could be recalled following a brief study period. Instructions emphasized that the pictures could be moved during the study period and placed in any position on the board. The children were encouraged to do anything during the study period they thought would help them remember the pictures better. Following a threeminute study period during which the experimenter left the testing room, the pictures were covered and recall (with no constraints on order) was recorded.

Following the test for immediate recall, each subject engaged in a series of reading and spelling activities designed to be of equivalent difficulty for children in each reading group. The tasks involved reading and spelling isolated words that varied in difficulty between reading groups. This interim period lasted for 10 minutes, after which the children were again tested for recall of the stimulus pictures.

\section{Procedure - Second \\ Experimental Session}

Prior to beginning the second session, which was held approximately 48 hours following the first session, the children were told that they would be "doing something different today." Each subject was shown the four hardboard strips and was told that they would be used to help play a sorting game. Each child was also shown four stacks of stimulus cards and was told that all of the stacks had the same cards in them. The experimenter then placed the cards from one of the stacks in an oblong array in front of each child and asked him to name them. The child was told to sort the pictures into four different groups of things that "go together in some way." Each child was instructed to place each group on one of the blue squares of a hardboard strip. When the child was finished sorting one stack of cards, he was told to move them aside and begin another stack. The object of the game was to see how many stacks the child could sort in three minutes.

While the subjects sorted the cards, the experimenter left the testing room. After the sorting period, recall was taken as in the first session. Delayed recall was also assessed following a 10 -minute interim period similar to that of the first session.

\section{Response Measures}

For each of the tasks, the basic response measure was simply the number of items correctly recalled. The tendency to cluster the material by category during recall was measured by the ratio of repetition (RR), which is defined by $r /(N-1)$, where $r=$ the number of category pairs occurring contiguously in recall, and $N=$ the total number of items recalled.

Following the study trial in the first session, the spatial arrangement of the pictures was examined for evidence that the subject had grouped the stimuli together in categories as an aid in studying. Stimuli were judged to be paired together if they were placed next to one another in the array. An index of clustering during the study period was obtained by dividing the number of category pairs adjacent to one another by the total number of pairs possible (20).

\section{RESULTS}

A preliminary question of interest was whether there were differences between groups in their rate of sorting the cards into categories during the orienting task. The index of sorting rate was the total number of cards a child was able to sort in a three-minute period. For the good readers the mean number of cards sorted was 86.9 , while for the poor readers it was 84.1 . This difference is not significant, $t(36)=.96$.

Immediate and delayed recall scores for both groups of children are presented in Table 1. The pattern of results was similar for both recall 
TABLE 1. Immediate and delayed recall scores for good and poor readers in both experimental conditions.

\begin{tabular}{|c|c|c|c|c|c|c|c|c|}
\hline \multirow[b]{3}{*}{ Recall scores } & \multicolumn{4}{|c|}{ Control condition } & \multicolumn{4}{|c|}{ Orienting task condition } \\
\hline & \multicolumn{2}{|c|}{$\begin{array}{l}\text { Good } \\
\text { readers }\end{array}$} & \multicolumn{2}{|c|}{$\begin{array}{l}\text { Poor } \\
\text { readers }\end{array}$} & \multicolumn{2}{|c|}{$\begin{array}{l}\text { Good } \\
\text { readers }\end{array}$} & \multicolumn{2}{|c|}{$\begin{array}{c}\text { Poor } \\
\text { readers }\end{array}$} \\
\hline & Mean & SD & Mean & SD & Mean & SD & Mean & SD \\
\hline Immediate & 16.9 & 3.5 & 13.4 & 2.6 & 17.4 & 2.2 & 17.9 & 2.3 \\
\hline Delayed & 15.3 & 3.1 & 12.3 & 2.9 & 17.3 & 2.3 & 16.6 & 2.7 \\
\hline
\end{tabular}

measures and provides clear support for the hypothesis that differences in recall between good and poor readers can be eliminated if both groups process the material to be remembered in the same manner. A repeated measures analysis of variance for the immediate recall scores indicated that the main effects of both condition, $F(1,36)=15.7, p<.001$, and group, $F(1,36)=6.2$, $p<.02$, were significant. There was also a strong group $\times$ condition interaction, $F(1,36)=10.3$, $p<.01$. Application of the Newman-Keuls test for individual comparisons indicated that the poor readers recalled significantly fewer items $(p<.01)$ than the good readers in the control condition. In the orienting condition, however, the reading disabled children actually recalled slightly more items than the children in the control group. In like manner, there were significant effects of condition, $F(1,36)=25.6$, $p<.001$, group, $F(1,36)=10.2, p<.01$, and group $x$ condition interaction, $F(1,36)=8.4, p<.01$ in the delayed recall data. Newman-Keuls comparisons showed that the recall differences between groups were significant only for the control condition.

That individual differences in the use of organizational strategies contributed importantly to the recall differences obtained in the free study condition is supported by an analysis of both study period and recall clustering scores. First, there were striking differences between groups in the tendency to cluster the stimuli together as a study aid. The median study period clustering score for the good readers was $\mathbf{8 0}$, while for the reading disabled children it was. 10 .
Analysis of this difference by means of a MannWhitney test indicated that it was reliable, $U=105, p<.02$. To compare the percentage of children in each reading group who used clustering as an intentional memorization activity, children of both groups were dichotomized into clusterers and nonclusterers. Because it was possible to obtain a small clustering score simply by engaging in some random movement of the cards, children with clustering scores below .20 were considered to have obtained their score by chance. When the children were divided on this basis, $68 \%$ of the good readers were classified as clusterers, while only $31 \%$ of the reading disabled children were so classified (Fisher exact test, $p=.024$ ).

The recall clustering scores of both groups for both experimental conditions are presented in Table 2. As for the recall data, there were significant group, $F(1,36)=5.0, p<.05$, condition, $F(1,36)=44.3, p<.001$, and group $\times$ condition, $F(1,36)=10.6, p<.01$, effects for clustering scores on both immediate and delayed recall ( $F$ values for delayed recall were 4.7, 24.8, 5.0 , respectively). Individual comparisons indicated that the control condition clustering scores of good and poor readers were significantly different from one another $(p<.01)$ for both types of recall. It is clear that the orienting task instructions had a positive effect on the recall clustering scores of both groups although the significant interaction terms indicate that the poor readers actually benefited more from performing the task than did the good readers. 


\begin{tabular}{|c|c|c|c|c|c|c|c|c|}
\hline \multirow[b]{3}{*}{ Clustering scores } & \multicolumn{4}{|c|}{ Control condition } & \multicolumn{4}{|c|}{ Orienting task condition } \\
\hline & \multicolumn{2}{|c|}{$\begin{array}{l}\text { Good } \\
\text { readers }\end{array}$} & \multicolumn{2}{|c|}{$\begin{array}{l}\text { Poor } \\
\text { readers }\end{array}$} & \multicolumn{2}{|c|}{$\begin{array}{l}\text { Good } \\
\text { readers }\end{array}$} & \multicolumn{2}{|c|}{$\begin{array}{c}\text { Poor } \\
\text { readers }\end{array}$} \\
\hline & Mean & $S D$ & Mean & SD & Mean & $S D$ & Mean & SD \\
\hline Immediate recall & .63 & .19 & .44 & .20 & .74 & .09 & .75 & .08 \\
\hline Delayed recall & .66 & .22 & .50 & .21 & .75 & .08 & .74 & .10 \\
\hline
\end{tabular}

\section{DISCUSSION}

This research provides support for the hypothesis that recall performance of reading disabled children on tasks requiring rote memory for nonmeaningful items is limited by their failure to employ efficient information processing strategies. The pattern of results from the free study condition replicates the results from an earlier study (Torgesen 1977) based on a sample of children from an entirely different geographical and cultural region of the country. This suggests that the tendency to use organizational strategies on this particular memory task is a relatively stable aspect of psychological difference between children of normal intelligence who have successfully attained beginning reading (word recognition) skills and those children of equivalent IQ who have not achieved the same level of skill.

The fact that recall of the good and poor readers was essentially equivalent following the orienting task is logically necessary to the conclusion that differences in level of processing of the stimuli was a major factor underlying the differences in recall in the free study condition (Belmont \& Butterfield 1977). That is, the orienting task was introduced as a control to ensure that children in both reading groups processed the stimuli in the same manner, and the effect of the control was to eliminate differences in recall. These results are consistent not only with major theoretical accounts of memory processes (Craik \& Lockhart 1972) but also with data from research on memory development in normal children (Lange \& Hultsch 1970).

Although it seems most accurate to interpret the group $\times$ condition interaction in recall performance in terms of the orienting task's influence on level of semantic processing, certain features of the experimental design make other interpretations potentially possible. For example, since the tasks were given in a fixed order to all children, the elimination of recall differences in the second session may have been the simple result of repeated testing, or practice effects. This interpretation seems untenable for two reasons. First, it requires the assumption that the poor readers can profit more from repeated exposure to experimental tasks than good readers. Research using a memory paradigm with poor learners in the Soviet Union (Egorova, cited in Wosniak 1975) indicates that children with learning problems are less able to profit from repeated exposure to a task than normal control groups. Second, the improvement in recall scores by the poor readers was accompanied by a parallel increase in recall clustering scores. Thus the poor readers not only recalled better, but their recall also followed a different pattern in the second session. The consistency of the changes in recall and recall clustering strongly supports the view that the main effect of the orienting task was to induce the children to encode the stimuli in terms of their categorical structure, which led to the use of this structure as an aid in recall.

Another difficulty in interpreting results within any incidental learning paradigm such as 
401

the one used in this study results from the possibility that the learning may not be entirely incidental (Postman 1964). That is, some children may have had various kinds of implicit sets for recall and may have been actually preparing for recall during the orienting task. If some of the children did anticipate the recall requirement in the second session, it is still difficult to account for the elimination of recall differences between reading groups on this basis. For example, direct questioning revealed that only two children, both good readers, reported any expectation of recall following the orienting task. In addition, observation of the children during the sorting activity indicated that none of them engaged in such simple mnemonic strategies as verbal labeling and rehearsal. Almost all children were fully occupied with the sorting activity during the entire three-minute period.

The usefulness of the results reported here derives mainly from the information they provide about some of the processes that may be responsible for the frequently reported memory deficits of poor readers. Since the success of the currently popular diagnostic-prescriptive approach to the remediation of reading disabilities requires an understanding of the psychological processes underlying poor performance on various psychometric instruments (Senf 1973), consideration of the kinds of processing deficiencies investigated in this study is extremely important. This study suggests that, at least for some kinds of memory problems, it may be inaccurate to speak of "specific disabilities" in memory per se and more accurate to think in terms of the reading disabled child's failure to approach certain kinds of cognitive tasks in an efficient manner. Like many experimental memory tasks, the attainment of beginning reading skills involves a heavy component of rote learning (Gibson \& Levin 1975, West 1975). Thus it is possible that children who experience problems learning to read do so for some of the same reasons our sample performed poorly in the present study. They fail to engage in certain types of goal-directed activity that are related to the efficient use of cognitive resources.

\section{ABOUT THE AUTHOR}

Joseph K. Torgesen obtained his PhD in psychology from the University of Michigan in 1976. He is currently an assistant professor in the school psychology program of the Department of Psychology at Florida State University. Harry Murphy is a PhD candidate in the school psychology program at Florida State. He is currently pursuing research in applied behavior analysis with children. Charles Ivey received his BS degree in psychology from Florida State in 1977. Requests for reprints should be addressed to Dr. Torgesen at the Department of Psychology, Florida State University, Tallahassee, Fla. 32306.

\section{REFERENCES}

Belmont, J.M., Butterfield, E.C., The instructional approach to cognitive development. In R.V. Kail, J.W. Hagen (Eds.), Perspectives on the Development of Memory and Cognition. Hillsdale, N.J.: Erlbaum Associates, 1977.

Cattell, R.B., Cattell, A.K.S., Handbook for the Culture Fair Intelligence Test. Champaign, Ill.: Institute for Personality and Ability Testing, 1960

Craik, F.I.M., Lockhart, R.S., Levels of processing: A framework for memory research. Journal of Verbal Learning and Verbal Behavior, 1972, 11, 671-684.

Gibson, E.J., Levin, H., The Psychology of Reading. Cambridge: MIT Press, 1975.

Jastak, J.F., Bijou, S.W., Jastak, S.R., Wide Range Achievement Test (rev. ed.). Wilmington: Guidance Associates, 1965.

Lange, G.W., Hultsch, D.F., The development of free classification and free recall in children. Developmental Psychology, 1970, 3, 408 .

Posnansky, C.J., Category norms for verbal items in 25 cate gories for children in grades 2-6 (Publication No. 8). Boulder, Colo.: Institute for the Study of Intellectual Behavior, University of Colorado, 1974

Postman, L., Short-term memory and incidental learning. In A.W. Melton (Ed.), Categories of Human Learning. New York: Academic Press, 1964.

Senf, G.M., An information-integration theory and its application to normal reading acquisition and reading disability. In N.D. Bryant, C.E. Kass (Eds.), Leadership Training Institute in Learning Disabilities: Final Report (Vol.2). Tucson, Ariz.: University of Arizona, 1972.

Tarver, S.G., Hallahan, D.P., Kauffman, J.M., Verbal rehearsal and selective attention in children with learning disabilities: A developmental lag. Journal of Experimental Child Psychology, 1976, 22, 375-385.

Torgesen, J.K., Problems and prospects in the study of learning disabilities. In M. Hetherington, J. Hagen (Eds.) Review of Child Development Research (Vol. 5). New York: Russell Sage Foundation, 1975.

Torgesen, J.K., The role of non-specific factors in the task performance of learning disabled children: A theoretical assessment. Journal of Learning Disabilities, 1977, 10, 27-34.

Torgesen, J.K., Memorization processes in reading disabled children. Journal of Educational Psychology, 1977, 69, 571-578.

Torgesen, J.K., Goldman, T., Rehearsal and short-term memory in reading disabled children. Child Development, $1977,48,56-60$.

West, R.F., Cognitive development and reading processes (Developmental Report \#76). Ann Arbor, Mich.: Developmental Program, Department of Psychology, University of Michigan, 1975.

Wozniak, R.H., Psychology and education of the learning disabled child in the Soviet Union. In W.M. Cruickshank, D.P. Hallahan (Eds.), Perceptual and Learning Disabilities in Children (Vol.1). Syracuse: Syracuse University Press, 1975 